\title{
Chapter 3 \\ Lean Manufacturing Implementation in Ceramic Industry: A Case Study
}

\author{
Jaiprakash Bhamu, Jagdish Bhadu, and Kuldip Singh Sangwan (i)
}

\begin{abstract}
This paper aims at proving that lean manufacturing can be successfully implemented in a semi-process industry, to reduce defects, waste, waiting time, processing time, inventory, and space. A case study was performed on a medium sized ceramic industry which resulted in waiting time reduction by $32 \%$, processing time reduction by $1.02 \%$, reduction in inventory by $36 \%$, defects reduction (average) by $40.51 \%$, reduction in manpower by $6.85 \%$ and cost saving of US $\$ 0.61$ million in one financial year. It might represent new opportunities for lean practitioners/researchers who are interested in substantiating their lean endeavors in semi-process industries.
\end{abstract}

Keywords Lean manufacturing $\cdot$ Waste reductions $\cdot$ Value stream mapping

\subsection{Introduction}

The goal of lean manufacturing (LM) is to become highly responsive to customer demand by reducing the waste in human efforts, inventory, time to market and manufacturing space while producing quality products effectively and efficiently (Bhamu et al. 2012). The LM implementation was started with automobile industry and soon was adopted by other industries including textile, construction, medical, food, electrical \& electronics, furniture, and services (Bhamu and Sangwan 2014). The combined application of Value Stream Mapping tools (VSM and Kanban) has shown the waste reduction in textile enterprise and increase in inventory turnover that affects

\footnotetext{
J. Bhamu $(\varangle) \cdot$ J. Bhadu

Department of Mechanical Engineering, Engineering College Bikaner, Bikaner 334004, RJ, India e-mail: bhamujp@gmail.com

J. Bhadu

e-mail: erj.bhadu@gmail.com

K. S. Sangwan

Department of Mechanical Engineering, Birla Institute of Technology and Science, Pilani-Campus, Pilani 333031, RJ, India
} 
the operational profitability. Low inventory in terms of free space provides opportunities to expand production by adding more machinery (Carvalho et al. 2018). Though VSM has many benefits, but when applied mistakenly, it may generate poor results that lead to bad decisions, both technically and financially. The future opportunities for VSM implementation, especially with regard to increased productivity and reliability of this lean tool were also discussed (Yuvamitra et al. 2017). VSM has the capability to diagnose a system with a lean perspective and to identify the opportunities for various lean projects/tools. The author reported the improvement plan, highlighting key lean projects/tools to perform for achieving their vision (Sangwa and Sangwan 2018). Ongoing reforms in the power sector and expansion of distribution infrastructure has resulted in demand for insulators, especially high-tension insulators (33 kV and above). The Indian share of the USD three billion in global electric insulator market is expected to reach $25-30 \%$ by the end of 2019 at the compounded annual growth rate of 6.4\% (Rother and Shook 1999).

The LM has been adopted by all types of manufacturing systems; however, the implementation of lean manufacturing in the continuous process industry has been less partly because of certain difficulties in the implementation in these type of industries (Jimenez et al. 2011). The application of lean manufacturing in ceramic industries (a semi-process industry) is challenging, as first half of the process is continuous type and the second half is discrete part manufacturing. The defective ceramic products cannot be reworked and recycled, and hence pose great threat to the environment. In addition, it leads to the loss of resources and missed opportunity cost. Therefore, the purpose of present work is to show the applicability of lean manufacturing in the ceramic sector through reduction of defects, waste, waiting time, processing time, inventory, rejections, and area required.

\subsection{Selection of the Case Company}

The case study was carried out at the company called XXX (a semi-process industry), is manufacturing high voltage and extra high voltage alumina porcelain insulators. Though it is challenging to implement LM in the industry, but it was selected as the top management was willing to implement lean manufacturing to improve productivity, quality and flexibility.

The production process was understood and a process sequence is created as shown in Fig. 3.1. The sequence of operation includes pre- kiln, kiln and post-kiln processes (Narapinji 2016). Tests are carried out before final inspection, which includes parallelism, eccentricity, visual defects, full dimension, and production specific requirement tests. The quality control passed insulators are packed in break proof wooden packs. The last process is loading and dispatching by the marketing department. 


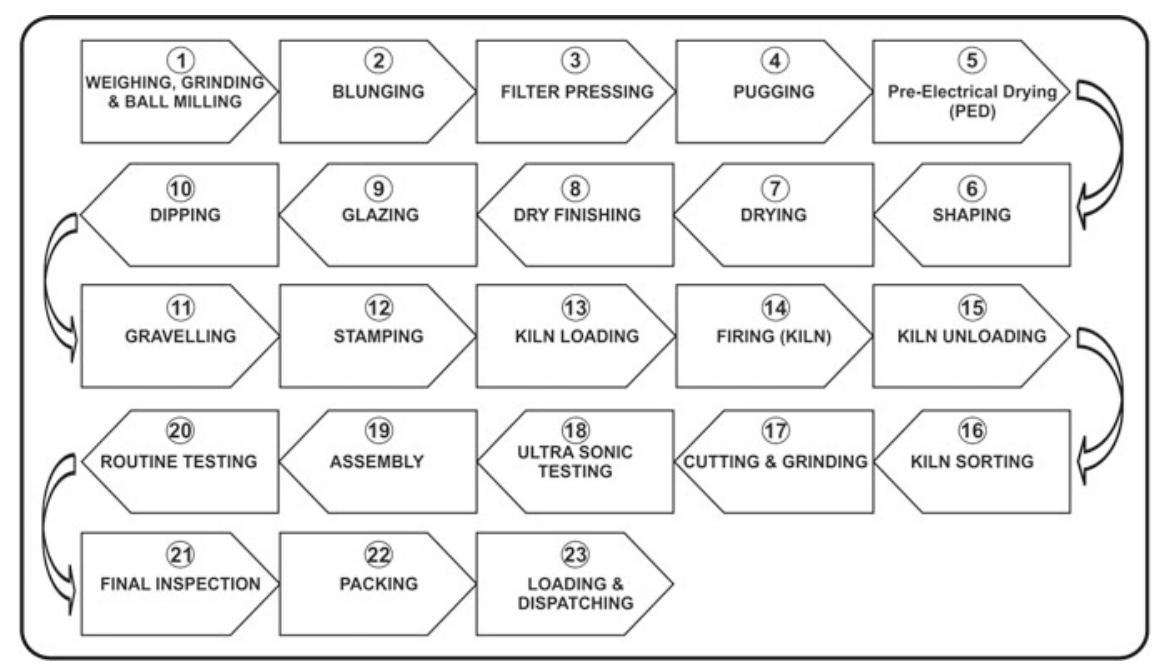

Fig. 3.1 Production process for the solid electric insulators

\subsection{Preparation and Analysis of Current Value Stream Map}

Current Value Stream Mapping (CVSM) serves as a starting point to help every person in the manufacturing system to identify waste. Value stream perspective means working on a bigger picture and trying to improve the whole process, not just individual processes (Fig. 3.2). There are two inventories mentioned below the inventory triangle in the current state map in which top data represent the inventory of solid core and below one indicates the inventories of all types of insulators. The following observations and analyses can be made from the current state of the organization:

- The processing time is approximately 13 days (18702.07 $\mathrm{min})$, while the waiting time is about 24.84 days. Apart from this, a large amount of inventory is piled up before drying, kiln sorting, cutting \& grinding, assembly, and final inspection processes/workstations.

- The inventory of 90 days locked at incoming material stores for the fear of unavailability of raw material.

- There is a large work-in-process (WIP) before major processes/workstations due to fear of unavailability of right quantity of finished goods. This also causes excess waiting time (24.84 days) and results in higher lead time.

Waste analysis is carried out for each process to find out the major waste, their causes and solutions. All the improvement initiatives/kaizens implemented to improve the processes have been discussed in the Sect. 5 of actions, results and discussion. 


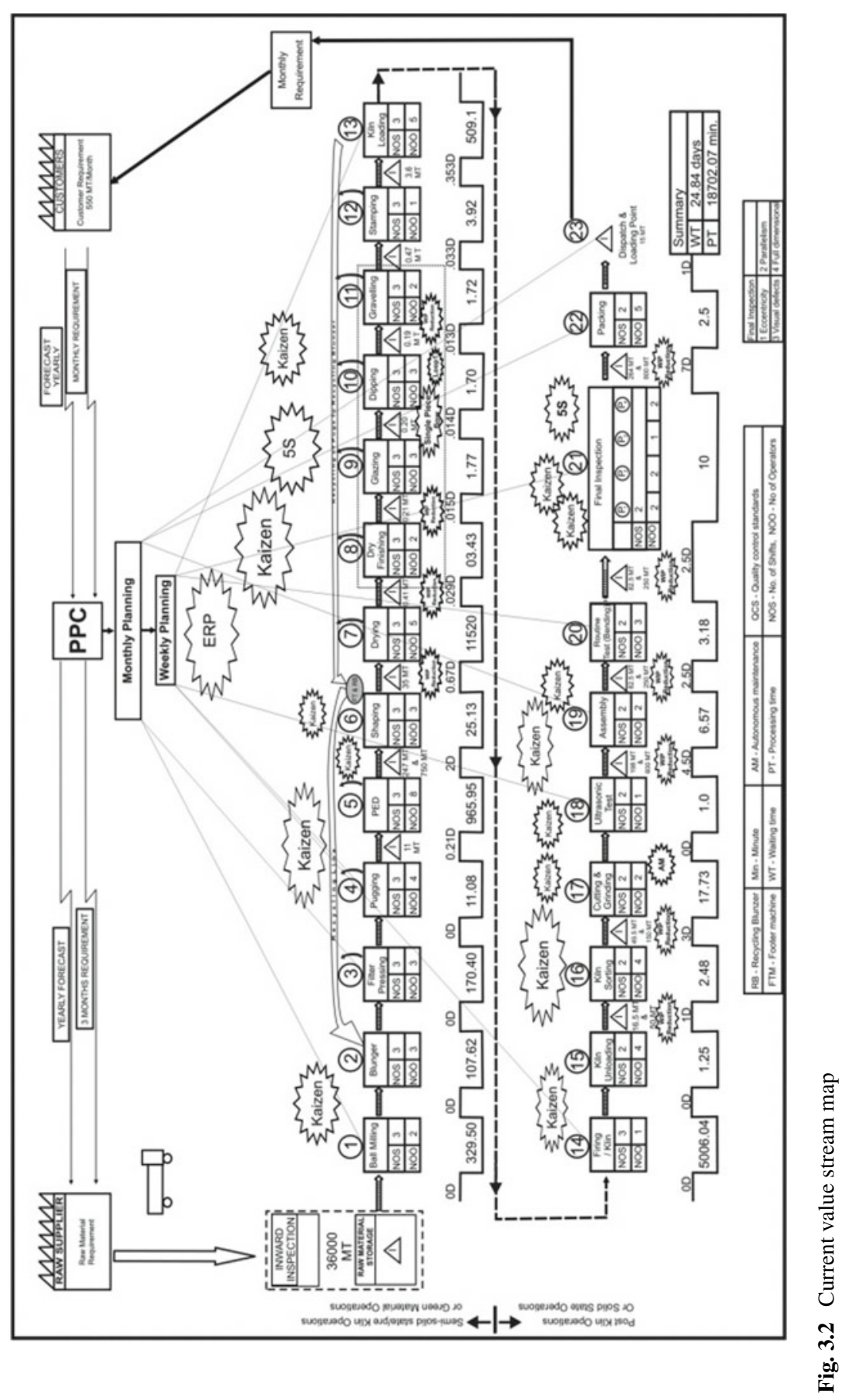




\subsection{Actions, Results and Discussion}

Based on the root causes identified in the previous section, specific kaizens were implemented as shown in Fig. 3.1 to reduce various types of wastes. Following general actions were also taken to improve productivity and reduce waste:

- The machine operators were trained to be multi-skilled with objective to start autonomous maintenance by the operators rather than the maintenance staff. It was started in three sections, cutting and grinding, shaping, and testing section.

- The importance of human resources in the lean implementation is very crucial. Shop floor supervisors were extensively trained to identify bottlenecks and take corrective actions to reduce the scrap and rework.

- Regular seminars and workshops were organized by external experts to improve communication among employees.

Some of the performance parameter improvements achieved are as follows:

\subsubsection{Processing Time}

The implementation of the kaizens and reduction in wastes has resulted in decreasing the processing time from $18,702.07$ to $18,510.51 \mathrm{~min}$, i.e. a reduction of $191.56 \mathrm{~min}$. Some of the implemented kaizens are: a rack with hook, knife, spanner, hopper and drainage pipe was placed between two ball mills (Process time (PT)) saved by $0.5 \mathrm{~min}$ ); the charging process has been improved by charging the ball mill simultaneously with raw materials and water (activity combination) (PT saved by $18 \mathrm{~min}$, energy saved); a digital clock and a siren were installed on each filter press to ensure it does not over-run (average PT saved by $20 \mathrm{~min}$, defect reduction); installation of electric powered bolt tighteners on every bending machine led to PT time saving (PT saved by $0.81 \mathrm{~min})$; the location of oil tanks were changed to bring them at their point of use (POU) for oiling of pug ends (PT saved by $10 \mathrm{~min}$ ); permanent attachment were added to ball mills for unloading of slurry (PT saved by $13 \mathrm{~min}$ ); application of wire mesh and covering both the sides of the insulator with polythene started before the pugs were loaded in the PED (PT saved by $60 \mathrm{~min}$ ); improved insulator cleaning method (PT saved by $30 \mathrm{~min}$ ).

\subsubsection{Waiting Time and Work-in-Process Reduction}

Reduction in defects resulted in reduction of raw material inventory and WIP inventory at many workstations. The introduction of one piece flow from workstation 8 (dry Finishing) to 11 (gravelling) brought down the waiting time (WT), significantly. Overall waiting time is reduced from 24.84 to 16.75 days, i.e. an improvement of 
8.09 days $(32.56 \%)$ which is very significant. This has been achieved mainly by implementing following kaizens:

- After PED, the pugs were kept in the pug yard for some time with covering of polythene. This step was removed and pugs were directly transferred to the dryer after shaping (waiting time reduced by 0.67 days, WIP to zero).

- Single piece flow was created among workstations 8-9-10-11 by scheduled leveling. The processing time of dry-finishing (workstation 8) was $206 \mathrm{~s}$ and for other three stations it was low (varying between 102 and $106 \mathrm{~s}$ ). One more station of dry-finishing was installed to make one piece flow. No new worker was assigned at new workstation 8 , but two persons who were working for batch shifting in previous layout were used to do the processing at new dry-finishing workstation. This helped in better handling of material, reduction in motion time, reduction in waiting time and drastic reduction in floor inventory (WIP reduced, waiting time reduced, handling defects reduced).

- The kiln department was facing shortage of space. Efforts were made to reduce the inventory on the shop floor. It was observed that inventory was high in the postkiln operations. Previously XXX was holding 7 days inventory in the warehouse because of poor communication and just-in-case tendency. Electronic information flow was started for the suppliers, which reduced the inventory to 6 days. It also helped in reducing order quantity and inventory at raw material stores in the company. Inventory level of raw material in store reduced to 2 months from 4 months. Inventory was reduced in pre and post kiln operations (Reduction in WIP along with reduction in WT after workstations 16, 18 and 21). Overall WIP is reduced by $36 \%$ starting from ball milling to packaging.

\subsubsection{Space Creation}

Lean initiatives, particularly $5 \mathrm{~S}$ implementation, allowed a better use of the physical space and machinery and created $719 \mathrm{~m}^{2}$ space after the case study.

\subsubsection{Breakdown Reduction}

The gain in break down time in shaping, $\mathrm{C} \& \mathrm{G}$ and testing processes/workstations after autonomous maintenance implementation is shown in Table 3.1. 
Table 3.1 Average breakdown in the shaping workstation

\begin{tabular}{l|l|l|l}
\hline S. No. & Name of workstation & $\begin{array}{l}\text { Monthly average breakdown } \\
\text { before autonomous } \\
\text { maintenance (h) }\end{array}$ & $\begin{array}{l}\text { Monthly average breakdown } \\
\text { maintenance (h) }\end{array}$ \\
\hline 1 & Shaping & 6.14 & 3.52 \\
\hline 2 & C\&G & 7.60 & 3.90 \\
\hline 3 & Testing & 8.88 & 3.88 \\
\hline
\end{tabular}

\subsubsection{Defect Reduction}

Action/improvement initiatives were taken to reduce the defect/rejection rate. It was observed that the major defects/green rejections are in the category of Shed Bend, Shed Cut, Round Crack, Damaged Pug, Shaping, and handling rejections. The improvements of these initiatives are shown in Figs. 3.3, 3.4 and 3.5.

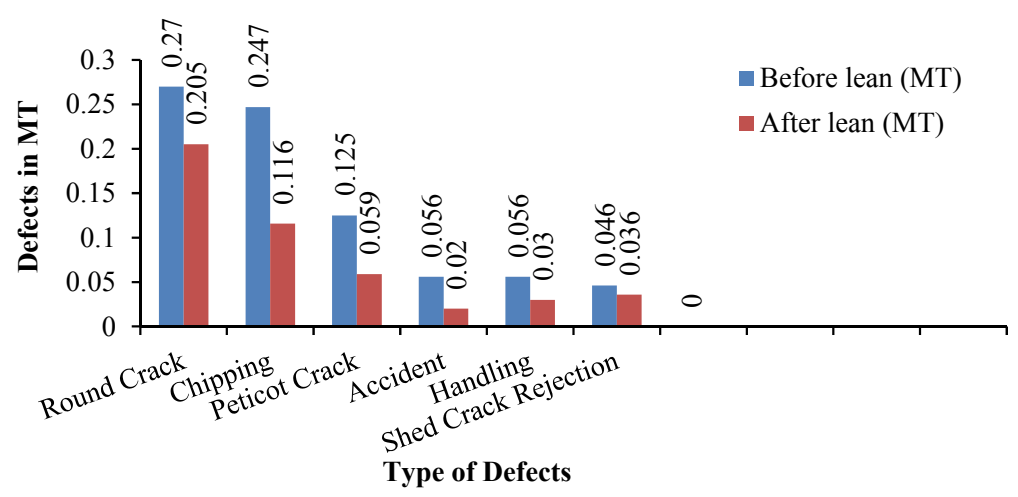

Fig. 3.3 Defect rate comparison at kiln workstation

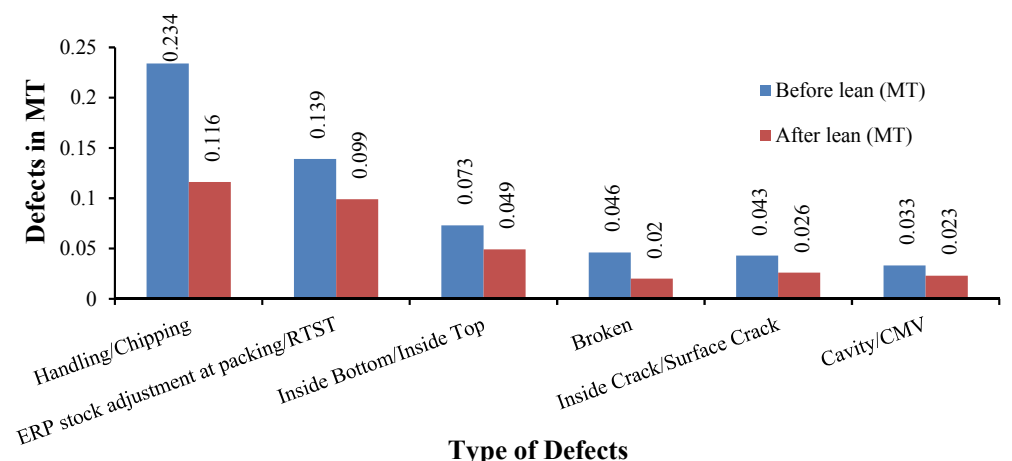

Fig. 3.4 Defect rate comparison in post kiln processes 


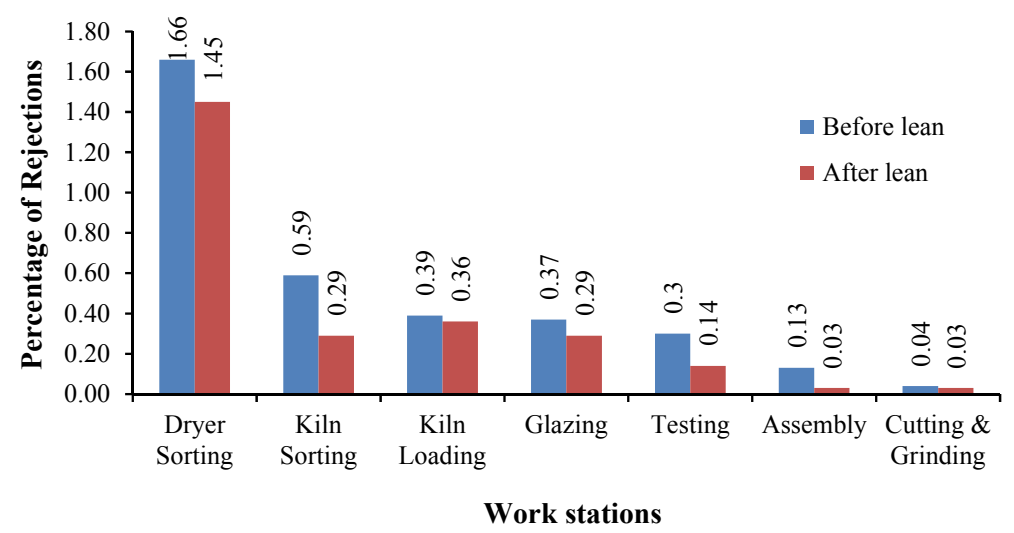

Fig. 3.5 Material handling rejections

\subsubsection{Kiln Rejection}

(See Fig. 3.3).

\subsubsection{Post Kiln Rejections}

(See Fig. 3.4).

\subsubsection{Material Handling Rejection}

Before lean manufacturing implementation, overall monthly post-kiln rejections was 3.258 MT and after LM implementation, it is $1.938 \mathrm{MT}$, i.e. an improvement of $40.51 \%$. These calculations are based on monthly average defects.

\subsubsection{Manpower Reduction}

One-piece flow in dry finishing, glazing, dipping and gravelling reduced manpower used for transfer of products. The pug machine operator was engaged in starting/stopping the belt after extrusion and in marking the pugs after the rack is completely loaded. He was effectively working for $10 \%$ of the time; assigned another machine. Present conveyor system was replaced with a hydraulic operated lift system by which one operator was reduced. Also, kaizens at testing, pugging and kiln resulted in reduction of manpower. The total reduction in manpower is $6.85 \%$ (68 from 73). 


\subsection{Conclusions}

This paper has shown the application of lean manufacturing in a semi-process industry. The organization has become flexible by eliminating wastes at various processes/workstations and responding to fluctuating customer demands quickly and efficiently. The various quantitative benefits of lean manufacturing implementation for the case organization are as:

- Waiting time reduction by $32 \%$

- Processing time reduction by $191.56 \mathrm{~min}$. (1.02\%)

- Reduction in inventory/WIP by $36 \%$

- Defects reduction (average) by $40.51 \%$

- Space creation for further use is $719 \mathrm{~m}^{2}$

- Reduction in manpower by $6.85 \%$

- Cost saving of US \$ 0.61 million in one financial year.

Qualitative benefits have also been observed in term of skill up gradation, team work, multi-skilling and improved morale of the employees.

\section{References}

Bhamu J, Sangwan KS (2014) Lean manufacturing: Literature review and research issues. Int J Oper Prod Manag 34(7):876-940

Bhamu J, Shailendra Kumar JV, Sangwan KS (2012) Productivity and quality improvement through value stream mapping: a case study of Indian automotive industry. Int J Prod Qual Manag 10(3):288-306

Carvalho CP, Carvalho DS, Silva MB (2018) Value stream mapping as a lean manufacturing tool: a new account approach for cost saving in a textile company. Int J Prod Manag Eng 7(1), (2018)

Jimenez E, Teieda A, Perez M, Martinez E (2011) Applicability of lean production with VSM to the Rioja wine sector\|. Int J Prod Res 50(7):1890-1904

Narapinji P (2016) Waste reduction in manufacturing process: a case study of ceramic factories in Thailand 5:126-132

Rother M, Shook J (1999) Learning to see: value stream mapping to add value and eliminate MUDA. The Lean Enterprise Institute, Brookline, MA

Sangwa NR, Sangwan KS (2018) Leanness assessment of organizational performance: a systematic literature review. J Manuf Technol Manag 25(6):1746-1761

Yuvamitra K, Lee J, Dong K (2017) Value stream mapping of rope manufacturing: a case study. Int J Manuf Eng 1-11 (2017) 
Open Access This chapter is licensed under the terms of the Creative Commons Attribution 4.0 International License (http://creativecommons.org/licenses/by/4.0/), which permits use, sharing, adaptation, distribution and reproduction in any medium or format, as long as you give appropriate credit to the original author(s) and the source, provide a link to the Creative Commons license and indicate if changes were made.

The images or other third party material in this chapter are included in the chapter's Creative Commons license, unless indicated otherwise in a credit line to the material. If material is not included in the chapter's Creative Commons license and your intended use is not permitted by statutory regulation or exceeds the permitted use, you will need to obtain permission directly from the copyright holder.

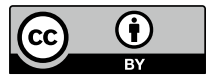

